\title{
Clinical analysis of cholangiocarcinoma patients receiving adjuvant radiotherapy
}

\author{
DANUPON NANTAJIT ${ }^{1}$, PORNWAREE TRIRUSSAPANICH ${ }^{1}$, SUNANTA ROJWATKARNJANA ${ }^{1}$, \\ KAMONWAN SOONKLANG ${ }^{2}$, POOMPIS PATTARANUTRAPORN ${ }^{1}$, \\ KANYANEE LAEBUA $^{1}$ and SASIKARN CHAMCHOD ${ }^{1}$
}

${ }^{1}$ Department of Radiation Oncology; ${ }^{2}$ Data Management Unit, Chulabhorn Hospital, Bangkok 10210, Thailand

Received October 13, 2015; Accepted April 21, 2016

DOI: $10.3892 / \mathrm{mco} .2016 .1072$

\begin{abstract}
Cholangiocarcinoma (CCA) or bile duct cancer is a rare cancer type in developed countries, while its prevalence is increased in southeast Asia, affecting 33.4 men and $\sim 12.3$ women per 100,000 individuals. CCA is one of the most lethal types of cancer. Neo-adjuvant and adjuvant therapies have been shown to have limited efficacy in improving the overall prognosis of patients. Radiotherapy has been reported to prolong the survival times of patients with certain characteristics. The present study retrospectively evaluated the medical records and follow-up data from 27 CCA patients who received radiotherapy at Chulabhorn Hospital (Bangkok, Thailand) between 2008 and 2014. A total of 14 patients underwent surgery followed by adjuvant chemoradiotherapy. Of the 27 CCA patients, 14 had intrahepatic CCA, 2 had extrahepatic CCA and 11 had hilar CCA. The 2-year survival rate was $40.7 \%$. Tumor resectability, clinical symptoms and the Eastern Cooperative Oncology Group performance status score were found to be indicative of patient prognosis. In addition, the planning target volume and biologically effective radiotherapy dose were of prognostic value; however, initial treatment response was ambiguous in predicting survival time. The findings of the present study suggested that the currently used radiotherapy protocols for CCA may require modification to improve their efficacy.
\end{abstract}

\section{Introduction}

Cholangiocarcinoma (CCA) is one of the most lethal cancer types, with a 5-year survival rate of $<5 \%(1,2)$. Mostly consisting of adenocarcinomas, CCAs are topographically categorized into two major subtypes, namely intrahepatic and extrahepatic CCAs, with the hilar subtype also being considered as

Correspondence to: Dr Sasikarn Chamchod, Department of Radiation Oncology, Chulabhorn Hospital, 54 Kamphaeng Phet 6, Talat Bang Khen, Lak Si, Bangkok 10210, Thailand

E-mail: sasikarnbm@yahoo.com

Key words: cholangiocarcinoma, adjuvant therapy, radiotherapy, survival, prognostic factor extrahepatic. CCA is rare in developed countries, with an incidence of $\sim 0.5-2$ per 100,000 individuals; however, intra- as well as extrahepatic CCA is common in southeast Asia, particularly Thailand. Compared with liver cancer, the prevalence of CCA is considered to account for $10-25 \%$ of liver cancer cases in the country, particularly in the northeastern region, where incidence rates of 36.3 and 87.7 per 100,000 individuals have been reported in women and men, respectively (3-6). The exact cause of bile duct cancer remains unknown; however, infection with the southeast Asian liver fluke (Opisthorchis viverrini) is considered a major risk factor for the development of intrahepatic CCA. Furthermore, liver cirrhosis, chronic hepatitis C virus infection, hepatolithiasis, smoking and obesity, as well as mutations of the K-ras and p53 genes, may also contribute to the development of intrahepatic CCA (7-11). While the risk factors for hilar and extrahepatic CCA largely remain elusive, excessive alcohol consumption has been reported to be a major risk factor for the development of extrahepatic CCA (12).

At present, complete surgical resection is considered as the only effective treatment available for CCA. Negative histological margins and well-differentiated tumor histology are associated with long-term survival of patients following tumor resection $(13,14)$. Liver transplantation combined with neoadjuvant chemoradiotherapy is another available option for effective CCA treatment $(15,16)$. In unresectable CCA, conventional treatment modalities, including chemotherapy and radiotherapy, may prolong patient survival; however, the results thus far are discouraging (17-19). An alternative radiation modality, stereotactic body radiation therapy, has also failed to improve the survival of unresectable CCA patients (20). Tumor -related hepatic failure due to disease recurrence is the leading cause of patient mortality, exceeding that of other causes combined, such as distant metastasis, infection or angiocholitis (21). For patients with resectable CCA, the effectiveness of postoperative adjuvant radiotherapy remains controversial, as diverse studies report either positive or null results. Although the debate regarding the benefit of radiotherapy for patients with CCA is ongoing, certain factors have been shown to affect treatment outcomes and patient survival (18,22-26). Age, ethnicity, tumor stage and year of diagnosis, as the numbers of patients receiving radiotherapy were growing, have been associated with the prognosis of CCA patients following radiotherapy (22). Negative margins, lymph 
node metastasis and tumor histopathology are also significant prognostic factors following treatment (27). The aim of the present study was to evaluate clinical factors which may affect the survival of CCA patients receiving radiotherapy treatment.

\section{Patients and methods}

Patient selection. The medical and follow-up records of CCA patients treated with radiotherapy between February, 2008 and June, 2014 at Chulabhorn Hospital (Bangkok, Thailand), were retrospectively reviewed. The patients were followed up until July, 2015, which was the end of the study period. Patients who had received and completed a radiotherapy course for primary CCA as part of their treatment scheme, as well as those who had received chemotherapy, either as a concurrent or an adjuvant treatment, in addition to radiotherapy, were included in the study. Patients who had received neo-adjuvant chemoradiotherapy or radiotherapy prior to surgery were excluded from the study. Gender, age at diagnosis, Eastern Cooperative Oncology Group (ECOG) performance score, tumor subtype, tumor stage, regional lymph node involvement, presence of distant metastasis, resection margin, histological grading, planning target volume (PTV) for radiotherapy and prescribed radiation dose were considered as independent variables, while patient survival time was considered as a dependent variable.

Statistical analysis. Patient data were presented using descriptive statics, and logistic regression analysis, the Yates' $\chi^{2}$ test and Fisher's exact test. The patient survival rate was analyzed using the Kaplan-Meier method and the log-rank test. The significance level was set at $\mathrm{P}<0.05$. Values are expressed as the mean \pm standard deviation (SD). All statistical analyses were performed using Stata/SE 12 software (StataCorp LP, College Station, TX, USA).

The present study was approved by the Committee on Human Rights Related to Research Involving Human Subjects of Chulabhorn Research Institute (Bangkok, Thailand). A waiver of informed consent was approved by the committee (reference no. 07/2557).

\section{Results}

Patient characteristics. A total of 39 patients diagnosed with CCA were treated at Chulabhorn Hospital during the study period; 2 patients were treated in 2008, when the hospital was initially established, 3 in 2009, 7 in 2010, 8 in 2011, 9 in 2012, 6 in 2013 and 4 in 2014 (until June). However, only 27 patients were included in the study after applying the inclusion and exclusion criteria. At diagnosis, the median age was 54 years (range, 42-77 years) and the mean age \pm SD was $55.2 \pm 9.04$ years. The clinical characteristics of the patients are listed in Table I. The majority of patients $(n=16)$ were men. A total of 14 patients had intrahepatic CCA, 11 had hilar CCA and the 2 remaining patients had extrahepatic CCA. According to the TNM staging system (based on the quidelines of the American Joint Committee on Cancer) the tumors of 4 patients were classified as stage I, those of 7 patients as stage II, those of 8 patients as stage III and those of 4 patients as stage IV, while stage was unknown for the remaining 4 patients. The tumor size ranged from
0.9 to $11.5 \mathrm{~cm}$. Furthermore, involvement of $1 \mathrm{lymph}$ node was found in 17 patients, while there was no lymph node involvement detected in the remaining 10 patients. None of the 27 patients had distant metastasis at initial diagnosis.

Treatment and outcome. Of the 27 patients, 15 were eligible for resection, of whom 14 underwent surgical treatment and 1 patient refused to undergo surgery. Among the patients who underwent surgical resection, 9 had positive resection margins and 5 had negative margins. In total, 23 patients received chemotherapy, either as an adjuvant therapy or concurrent chemoradiotherapy. Of these patients, 19 received 5-fluorouracil, 3 received gemcitabine and 1 received cisplatin with gemcitabine. Regarding radiotherapy, the patients received radiation doses of 46-66 Gy, depending on their condition (mean radiation dose, $48.3 \pm 6.3 \mathrm{~Gy}$ ). The dose per fraction was typically 1.8 or $2 \mathrm{~Gy}$; however, two patients received higher doses per fraction, 2.2 or $2.3 \mathrm{~Gy}$ each. One patient received stereotactic body radiation therapy (SBRT; 6 fractions of $9 \mathrm{~Gy}$ each). With the assumption of an $\alpha / \beta$ ratio of $10 \mathrm{~Gy}$, the calculated biologically effective dose (BED) ranged from 55.2 to $102.6 \mathrm{~Gy}$.

Due to the low 5-year survival rate of CCA patients and a median survival of 14 months (28), the 2-year survival rate of the patients of the present study was determined. The survival rate of the patients is shown in Fig. 1. Furthermore, statistical analysis of factors affecting survival was performed within the patients' survival period. Among the 27 cases, the mean and median survival times were 699 and 637 days (23.0 and 20.9 months), respectively. A number of factors appeared to be prognostic for survival: Resectability of the tumor, patient ECOG performance status and clinical symptoms were the main indicators of prognosis (Table I). In terms of radiotherapy, PTV and BED applied during treatment were also significantly associated with patient survival (Table II).

\section{Discussion}

CCA is a lethal cancer that predominantly affects individuals in developing countries; to date, means to reduce its incidence have not been implemented. Numerous potential prognostic factors have been suggested for patients with CCA. Orthotopic liver transplantation along with chemoradiotherapy have significantly improved overall survival in CCA patients, with fewer complications of locoregional dissemination and tumor recurrence; thus, this approach is considered as standard treatment procedure for CCA $(29,30)$. However, this option may not be feasible for all patients; conventional therapies, including surgical resection, chemotherapy and radiotherapy, may remain useful for CCA patients with certain characteristics.

The clinical condition of affected patients provides an initial indicator regarding the prediction of survival; as previously reported, the ECOG status and clinical symptoms provide information regarding the severity of the disease and treatment outcome (31). It has been reported that patients considered suitable for surgery also have a higher survival rate (32). However, in the present study, neither lymph node involvement nor histological grading were predictive factors for patient survival according to the statistical analysis. 
Table I. Characteristics and factors affecting the survival of patients with cholangiocarcinoma.

\begin{tabular}{|c|c|c|c|c|}
\hline Factors & $\mathrm{n}$ & $\begin{array}{c}\text { 2-year survival } \\
\mathrm{n}(\%)\end{array}$ & $\begin{array}{c}\text { P-value } \\
\text { (logistic regression) }\end{array}$ & $\begin{array}{c}\text { P-value } \\
\left(\chi^{2} / \text { Fisher's exact test }\right)\end{array}$ \\
\hline Gender & & & 0.052 & 0.061 \\
\hline Male & 16 & $4(25.0)$ & & \\
\hline Female & 11 & $7(63.6)$ & & \\
\hline Age (years) & & & 0.080 & 0.159 \\
\hline$\leq 55$ & 14 & $8(57.1)$ & & \\
\hline$>55$ & 13 & $3(23.1)$ & & \\
\hline Performance status ${ }^{\mathrm{a}}$ & & & 0.028 & 0.018 \\
\hline 0 & 17 & $10(58.8)$ & & \\
\hline $1-2$ & 10 & $1(10.0)$ & & \\
\hline TNM stage & & & 0.485 & 0.696 \\
\hline $\mathrm{T} 1 / \mathrm{T} 2 / \mathrm{Tx}$ & 15 & $7(46.7)$ & & \\
\hline T3/T4 & 12 & $4(33.3)$ & & \\
\hline Subtype & & & 0.816 & 1.000 \\
\hline Intrahepatic & 14 & $6(42.9)$ & & \\
\hline Extrahepatic/hilar & $2 / 11$ & $5(38.5)$ & & \\
\hline Resectability & & & 0.032 & 0.047 \\
\hline Resectable & 15 & $9(60.0)$ & & \\
\hline Unresectable & 12 & $2(16.7)$ & & \\
\hline Clinical symptoms & & & 0.016 & 0.028 \\
\hline No & 14 & $9(64.3)$ & & \\
\hline Yes & 13 & $2(15.4)$ & & \\
\hline Lymph node involvement & & & 0.952 & 1.000 \\
\hline No & 10 & $4(40.0)$ & & \\
\hline N1 & 17 & $7(41.2)$ & & \\
\hline Histological grading & & & 0.060 & 0.066 \\
\hline Well-differentiated & 11 & $7(63.6)$ & & \\
\hline Moderately -poorly differentiated & 7 & $1(14.3)$ & & \\
\hline Largest tumor diameter $(\mathrm{cm})$ & & & 0.952 & 1.000 \\
\hline$\leq 4$ & 17 & $7(41.2)$ & & \\
\hline$>4$ & 10 & $4(40.0)$ & & \\
\hline Lesion & & & 0.970 & 1.000 \\
\hline Single & 22 & $9(40.9)$ & & \\
\hline Multiple & 5 & $2(40.0)$ & & \\
\hline
\end{tabular}

${ }^{\mathrm{a} A c c o r d i n g}$ to the Eastern Cooperative Oncology Group classification.

The efficacy of radiotherapy in the treatment of CCA has been questioned; it has previously been reported that postoperative radiotherapy exerts a limited effect on the survival of patients with hilar CCA (33). However, radiation as an adjuvant or palliative treatment appears to confer a survival advantage in patients with intra- or extrahepatic CCA $(22,24,33,34)$. Radiotherapy has been shown to prolong patient survival by $\sim 4$ months in unresectable intrahepatic CCA (35). It has also been suggested that liver transplantation with neoadjuvant chemoradiotherapy may achieve improved survival rates in patients with hilar CCA in comparison with surgical resection (36).
In the present study, retrospective analysis of the data of CCA patients who had received radiotherapy was performed. Although TNM-staging did not provide any prognostic information, PTV, which was adjusted according to the tumor size, was a significant predictive factor $(\mathrm{P}<0.05)$. From this, it can be deduced that a smaller tumor size is associated with a higher survival rate. In addition, although patient survival was not significantly associated with the total therapeutic dose, once the total radiation doses and fractionation frequencies were converted into BED, the difference in survival became significant between patients who received a BED $>60$ vs. those who received a lower $\mathrm{BED}$. The $\mathrm{BED}$ is prescribed based on the 
Table II. Radiotherapy factors affecting the survival of cholangiocarcinoma patients.

\begin{tabular}{|c|c|c|c|c|}
\hline Factors & $\mathrm{n}$ & $\begin{array}{c}\text { 2-year survival, } \\
\mathrm{n}(\%)\end{array}$ & $\begin{array}{c}\text { P-value } \\
\text { (logistic regression) }\end{array}$ & $\begin{array}{c}\text { P-value } \\
\left(\chi^{2} / \text { Fisher's exact test }\right)\end{array}$ \\
\hline Radiotherapy dose (Gy) & & & 0.080 & 0.159 \\
\hline$\leq 54$ & 14 & $8(57.1)$ & & \\
\hline$>54$ & 13 & $3(23.1)$ & & \\
\hline Planning target volume $\left(\mathrm{cm}^{3}\right)$ & & & 0.016 & 0.028 \\
\hline$\leq 600$ & 14 & $9(64.3)$ & & \\
\hline$>600$ & 13 & $2(15.4)$ & & \\
\hline Biologically effective dose (Gy) & & & 0.019 & 0.022 \\
\hline$\leq 60$ & 12 & $8(66.7)$ & & \\
\hline$>60$ & 15 & $3(20.0)$ & & \\
\hline Treatment response after 3 months & & & 0.047 & 0.056 \\
\hline Complete response & 6 & $5(83.3)$ & & \\
\hline $\begin{array}{l}\text { Partial response, stable and } \\
\text { progressive disease }\end{array}$ & 19 & $6(31.6)$ & & \\
\hline
\end{tabular}

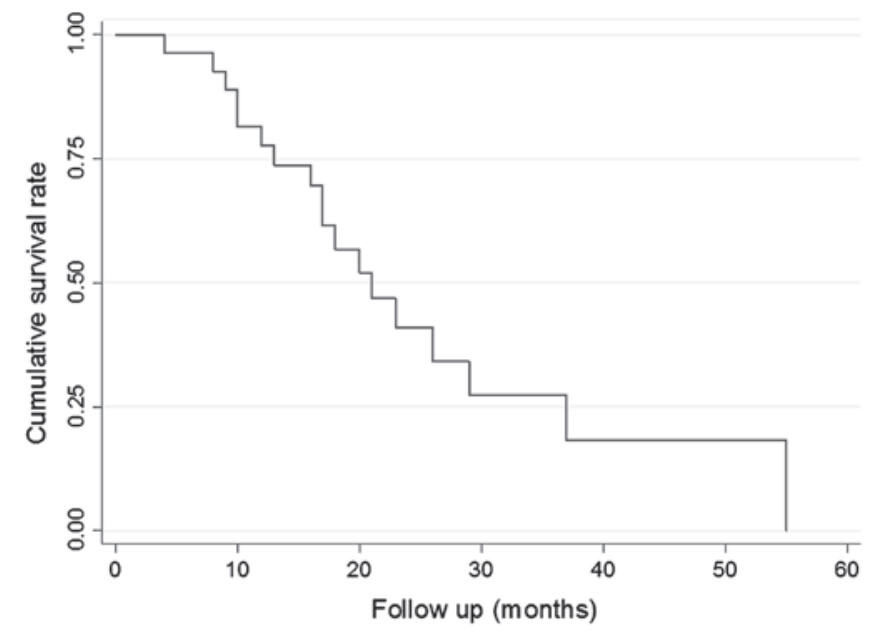

Figure 1. Cumulative survival rate of the 27 patients with cholangiocarcinoma.

clinicopathological condition of each patient and corresponds with the tumor status, including its resectability or whether there is residual tumor following surgery; thus, a larger BED was associated with poor patient prognosis. The fact that a larger BED translated to a poorer prognosis also indicated that current radiotherapy protocols may not address the severity of the disease, and that radiotherapy is ineffective against CCA as previously hypothesized (37). It has been reported that SBRT may achieve higher survival rates for selected patients (38); SBRT concurrent with gemcitabine has also been suggested to be a promising approach (39).

Based on logistic regression analysis, treatment response at 3 months was considered to be of prognostic value $(\mathrm{P}=0.047)$; however, when analyzed using the Fisher's exact test, this factor could no longer be used to predict between-group differences $(\mathrm{P}=0.056)$. Re-grouping between complete and partial response vs. stable and progressive disease also revealed no significant difference $(\mathrm{P}=0.325)$. Thus, based on the findings of the present study, initial treatment response may be of limited value in determining patient prognosis. Future studies using a larger patient cohort may help determine whether patient response at 3 months after treatment may be used to predict the prognosis.

CCA is a heterogeneous cancer type and complete surgical resection is the most effective treatment for either perihilar or peripheral CCA. In addition to surgery, the majority of the patients undergo postoperative adjuvant treatment. Although these adjuvant treatments have conferred certain survival benefit, the actual standard protocols vary, particularly regarding radiotherapy; at present, there is no consensus regarding the optimal definition of target contouring, radiation dose and fractionation schedule. Novel radiological modalities, including dynamic computed tomography (CT), magnetic resonance cholangiopancreatography and positron emission tomography/CT, have been developed and have become useful for target contouring. Moreover, liver motion is a critical factor that requires consideration during contouring (40-42). Fluoroscopy or 4D-CT have been proven to be useful in the precise definition of the internal target volume. All these technologies enhance the accuracy of radiation delivery and improve local tumor control. Further development of these procedures may improve the efficacy of radiotherapy for CCA.

Besides standard external beam radiotherapy, yttrium-90 radioembolization is currently used as an alternative procedure for radiation delivery. It may be employed for the treatment of intrahepatic CCA and has appeared to confer survival benefits to patients. Radioembolization has also been reported to transform unresectable into resectable tumors $(43,44)$. Therefore, the effectiveness of this approach for treating intrahepatic CCA should also be further investigated.

In conclusion, the present study investigated clinical characteristics of CCA patients, such as performance status, clinical symptoms and resectability of the tumor, as predictive factors of prognosis. Tumor volume, represented by PTV, and 
radiation dose delivered to the tumor, expressed as the BED, may be used as predictors of survival. CCA patients subjected to radiotherapy with a lower PTV and BED had higher 2-year survival rates. However, as these factors were adjusted based on tumor size and the clinicopathological status, increased survival rates may have been due to the lower degree of disease progression. Further studies involving larger patient numbers are required to further validate the findings of the present study.

\section{Acknowledgements}

The present study was supported by the Chulabhorn Hospital and Chulabhorn Foundation. The authors would like to thank Professor Pittayapoom Pattaranutraporn for initiating the study and for his insightful discussions concerning the study. A language editing service (Edanz) was used to copyedit the manuscript.

\section{References}

1. Patel T: Increasing incidence and mortality of primary intrahepatic cholangiocarcinoma in the United States. Hepatology 33: 1353-1357, 2001

2. Shaib YH, Davila JA, McGlynn K and El-Serag HB: Rising incidence of intrahepatic cholangiocarcinoma in the United States: A true increase? J Hepatol 40: 472-477, 2004.

3. Altekruse SF, McGlynn KA and Reichman ME: Hepatocellular carcinoma incidence, mortality, and survival trends in the United States from 1975 to 2005. J Clin Oncol 27: 1485-1491, 2009.

4. Mosconi S, Beretta GD, Labianca R, Zampino MG, Gatta G and Heinemann V: Cholangiocarcinoma. Crit Rev Oncol Hematol 69: 259-270, 2009.

5. Shin HR, Oh JK, Masuyer E, Curado MP, Bouvard V, Fang YY, Wiangnon S, Sripa B and Hong ST: Epidemiology of cholangiocarcinoma: An update focusing on risk factors. Cancer Sci 101 579-585, 2010.

6. Pattanathien P, Khuntikeo N, Promthet S and Kamsa-Ard S: Survival rate of extrahepatic cholangiocarcinoma patients after surgical treatment in Thailand. Asian Pac J Cancer Prev 14: 321-324, 2013.

7. Donato F, Gelatti U, Tagger A, Favret M, Ribero ML, Callea F, Martelli C, Savio A, Trevisi P and Nardi G: Intrahepatic cholangiocarcinoma and hepatitis $\mathrm{C}$ and $\mathrm{B}$ virus infection, alcohol intake and hepatolithiasis: A case-control study in Italy. Cancer Causes Control 12: 959-964, 2001.

8. O'Dell MR, Huang JL, Whitney-Miller CL, Deshpande V, Rothberg P, Grose V, Rossi RM, Zhu AX, Land H, Bardeesy N and Hezel AF: Kras (G12D) and p53 mutation cause primary intrahepatic cholangiocarcinoma. Cancer Res 72: 1557-1567, 2012

9. Sripa B, Kaewkes S, Sithithaworn P, Mairiang E, Laha T, Smout M, Pairojkul C, Bhudhisawasdi V, Tesana S, Thinkamrop B, et al: Liver fluke induces cholangiocarcinoma. PLoS Med 4: e201, 2007.

10. Watanapa P and Watanapa WB: Liver fluke-associated cholangiocarcinoma. Br J Surg 89: 962-970, 2002.

11. Welzel TM, Graubard BI, El-Serag HB, Shaib YH, Hsing AW, Davila JA and McGlynn KA: Risk factors for intrahepatic and extrahepatic cholangiocarcinoma in the United States: A population-based case-control study. Clin Gastroenterol Hepatol 5: 1221-1228, 2007.

12. Shaib YH, El-Serag HB, Nooka AK, Thomas M, Brown TD, Patt YZ and Hassan MM: Risk factors for intrahepatic and extrahepatic cholangiocarcinoma: A hospital-based case-control study. Am J Gastroenterol 102: 1016-1021, 2007.

13. Jarnagin WR, Fong Y, DeMatteo RP, Gonen M, Burke EC, Bodniewicz BS J, Youssef BA M, Klimstra D and Blumgart LH: Staging, resectability, and outcome in 225 patients with hilar cholangiocarcinoma. Ann Surg 234: 507-517, discussion 517-519, 2001.

14. Clary B, Jarnigan W, Pitt H, Gores G, Busuttil R and Pappas T: Hilar cholangiocarcinoma. J Gastrointest Surg 8: 298-302, 2004.
15. Sudan D, DeRoover A, Chinnakotla S, Fox I, Shaw B Jr, McCashland T, Sorrell M, Tempero M and Langnas A: Radiochemotherapy and transplantation allow long-term survival for nonresectable hilar cholangiocarcinoma. Am J Transplant 2: 774-779, 2002.

16. Khan SA and Thomas HC, Davidson BR and Taylor-Robinson SD: Cholangiocarcinoma. Lancet 366: 1303-1314, 2005.

17. Anderson CD, Pinson CW, Berlin J and Chari RS: Diagnosis and treatment of cholangiocarcinoma. Oncologist 9: 43-57, 2004.

18. Horgan AM, Amir E, Walter T and Knox JJ: Adjuvant therapy in the treatment of biliary tract cancer: A systematic review and meta-analysis. J Clin Oncol 30: 1934-1940, 2012.

19. Monson JR, Donohue JH, Gunderson LL, Nagorney DM, Bender CE and Wieand HS: Intraoperative radiotherapy for unresectable cholangiocarcinoma-the Mayo Clinic experience. Surg Oncol 1: 283-290, 1992.

20. Kopek N, Holt MI, Hansen AT and Hoyer M: Stereotactic body radiotherapy for unresectable cholangiocarcinoma. Radiother Oncol 94: 47-52, 2010

21. Moureau-Zabotto L, Turrini O, Resbeut M, Raoul JL, Giovannini M, Poizat F, Piana G, Delpero JR and Bertucci F: Impact of radiotherapy in the management of locally advanced extrahepatic cholangiocarcinoma. BMC Cancer 13: 568, 2013.

22. Shinohara ET, Mitra N, Guo M and Metz JM: Radiation therapy is associated with improved survival in the adjuvant and definitive treatment of intrahepatic cholangiocarcinoma. Int J Radiat Oncol Biol Phys 72: 1495-1501, 2008.

23. Pitt HA, Nakeeb A, Abrams RA, Coleman J, Piantadosi S, Yeo CJ, Lillemore KD and Cameron JL: Perihilar cholangiocarcinoma. Postoperative radiotherapy does not improve survival. Ann Surg 221: 788-797; discussion 797-798, 1995.

24. Shinohara ET, Mitra N, Guo M and Metz JM: Radiotherapy is associated with improved survival in adjuvant and palliative treatment of extrahepatic cholangiocarcinomas. Int J Radiat Oncol Biol Phys 74: 1191-1198, 2009.

25. Todoroki T, Ohara K, Kawamoto T, Koike N, Yoshida S, Kashiwagi H, Otsuka M and Fukao K.: Benefits of adjuvant radiotherapy after radical resection of locally advanced main hepatic duct carcinoma. Int J Radiat Oncol Biol Phys 46: 581-587, 2000.

26. Sagawa N, Kondo S, Morikawa T, Okushiba S and Katoh H: Effectiveness of radiation therapy after surgery for hilar cholangiocarcinoma. Surg Today 35: 548 -552, 2005.

27. Chen MF: Peripheral cholangiocarcinoma (cholangiocellular carcinoma): Clinical features, diagnosis and treatment. J Gastroenterol Hepatol 14: 1144-1149, 1999.

28. Su CH, Tsay SH, Wu CC, Shyr YM, King KL, Lee CH, Lui WY, Liu TJ and P'eng FK: Factors influencing postoperative morbidity, mortality and survival after resection for hilar cholangiocarcinoma. Ann Surg 223: 384-394, 1996.

29. Becker NS, Rodriguez JA, Barshes NR, O'Mahony CA, Goss JA and Aloia TA: Outcomes analysis for 280 patients with cholangiocarcinoma treated with liver transplantation over an 18-year period. J Gastrointest Surg 12: 117-122, 2008.

30. Salgia RJ, Singal AG, Fu S, Pelletier S and Marrero JA: Improved post-transplant survival in the United States for patients with cholangiocarcinoma after 2000. Dig Dis Sci 59: 1048-1054, 2014.

31. Thuluvath PJ,RaiR, Venbrux AC and Yeo CJ: Cholangiocarcinoma: A review. Gastroenterologist 5: 306-315, 1997.

32. Nakeeb A, Pitt HA, Sohn TA, Coleman J, Abrams RA, Piantadosi S, Hruban RH, Lillemoe KD, Yeo CJ and Cameron JL: Cholangiocarcinoma. A spectrum of intrahepatic, perihilar and distal tumors. Ann Surg 224: 463-473; discussion 473-465, 1996.

33. Zeng ZC, Tang ZY, Fan J, Zhou J, Qin LX, Ye SL, Sun HC, Wang BL, Li D, Wang JH, et al: Consideration of the role of radiotherapy for unresectable intrahepatic cholangiocarcinoma: A retrospective analysis of 75 patients. Cancer J 12: 113-122, 2006.

34. Ben-David MA, Griffith KA, Abu-Isa E, Lawrence TS, Knol J, Zalupski $M$ and Ben-Josef E: External-beam radiotherapy for localized extrahepatic cholangiocarcinoma. Int J Radiat Oncol Biol Phys 66: 772-779, 2006.

35. Chen YX, Zeng ZC, Tang ZY, Fan J, Zhou J, Jiang W, Zeng MS and Tan YS: Determining the role of external beam radiotherapy in unresectable intrahepatic cholangiocarcinoma: A retrospective analysis of 84 patients. BMC Cancer 10: 492, 2010. 
36. Rea DJ, Heimbach JK, Rosen CB, Haddock MG, Alberts SR, Kremers WK, Gores GJ and Nagorney DM: Liver transplantation with neoadjuvant chemoradiation is more effective than resection for hilar cholangiocarcinoma. Ann Surg 242: 451-458; discussion 458-461, 2005

37. Patel T: Cholangiocarcinoma. Nat Clin Pract Gastroenterol Hepatol 3: 33-42, 2006

38. Barney BM, Olivier KR, Miller RC and Haddock MG: Clinical outcomes and toxicity using stereotactic body radiotherapy (SBRT) for advanced cholangiocarcinoma. Radiat Oncol 7: 67, 2012.

39. Polistina FA, Guglielmi R, Baiocchi C, Francescon P, Scalchi P, Febbraro A, Costantin G and Ambrosino G: Chemoradiation treatment with gemcitabine plus stereotactic body radiotherapy for unresectable, non-metastatic, locally advanced hilar cholangiocarcinoma. Results of a five year experience. Radiother Oncol 99: 120-123, 2011

40. Lin G, Toh CH, Wu RC, Ko SF, Ng SH, Chou WC and Tseng JH: Combined hepatocellular cholangiocarcinoma: prognostic factors investigated by computed tomography/magnetic resonance imaging. Int J Clin Pract 62: 1199 -1205, 2008
41. Maccioni F, Martinelli M, Al Ansari N, Kagarmanova A, De Marco V, Zippi M and Marini M. Magnetic resonance cholangiography: past, present and future: A review. Eur Rev Med Pharmacol Sci 14: 721 -725, 2010.

42. Breitenstein S, Apestegui C and Clavien PA: Positron emission tomography (PET) for cholangiocarcinoma. HPB (Oxford) 10: $120-121,2008$.

43. Al-Adra DP, Gill RS, Axford SJ, Shi X, Kneteman N and Liau SS: Treatment of unresectable intrahepatic cholangiocarcinoma with yttrium-90 radioembolization: A systematic review and pooled analysis. Eur J Surg Oncol 41: 120-127, 2015.

44. Mouli S, Memon K, Baker T, Benson AB 3rd, Mulcahy MF, Gupta R, Ryu RK, Salem R and Lewandowski RJ: Yttrium-90 radioembolization for intrahepatic cholangiocarcinoma: safety, response and survival analysis. J Vasc Interv Radiol 24: 1227-1234, 2013. 